\title{
APPLICATION OF FRACTAL GEOMETRY IN EVALUATION OF EFFECTIVE STIMULATED RESERVOIR VOLUME IN SHALE GAS RESERVOIRS
}

\author{
GUANGLONG SHENG, ${ }^{*}$ YULIANG SU,,$\S$ WENDONG WANG, ${ }^{*}$ \\ FARZAM JAVADPOUR ${ }^{\dagger}$ and MEIRONG TANG ${ }^{\ddagger}$ \\ ${ }^{*}$ School of Petroleum Engineering \\ China University of Petroleum (East China), Qingdao 266580, P. R. China \\ ${ }^{\dagger}$ Bureau of Economic Geology, Jackson School of Geosciences \\ The University of Texas at Austin, Austin, TX 78713, USA \\ ${ }^{\ddagger}$ Research Institute of Oil Gas Technology \\ Changqing Oilfield, Xi'an 710021, P. R. China \\ \$sylupc@gmail.com
}

Received February 3, 2017

Revised April 13, 2017

Accepted April 17, 2017

Published June 5, 2017

\begin{abstract}
According to hydraulic-fracturing practices conducted in shale reservoirs, effective stimulated reservoir volume (ESRV) significantly affects the production of hydraulic fractured well. Therefore, estimating ESRV is an important prerequisite for confirming the success of hydraulic fracturing and predicting the production of hydraulic fracturing wells in shale reservoirs. However, ESRV calculation remains a longstanding challenge in hydraulic-fracturing operation. In considering fractal characteristics of the fracture network in stimulated reservoir volume (SRV),
\end{abstract}

\footnotetext{
${ }^{\S}$ Corresponding author.

This is an Open Access article published by World Scientific Publishing Company. It is distributed under the terms of the Creative Commons Attribution 4.0 (CC-BY) License. Further distribution of this work is permitted, provided the original work is properly cited.
} 
G. Sheng et al.

this paper introduces a fractal random-fracture-network algorithm for converting the microseismic data into fractal geometry. Five key parameters, including bifurcation direction, generating length $(d)$, deviation angle $(\alpha)$, iteration times $(N)$ and generating rules, are proposed to quantitatively characterize fracture geometry. Furthermore, we introduce an orthogonal-fractures coupled dual-porosity-media representation elementary volume (REV) flow model to predict the volumetric flux of gas in shale reservoirs. On the basis of the migration of adsorbed gas in porous kerogen of REV with different fracture spaces, an ESRV criterion for shale reservoirs with SRV is proposed. Eventually, combining the ESRV criterion and fractal characteristic of a fracture network, we propose a new approach for evaluating ESRV in shale reservoirs. The approach has been used in the Eagle Ford shale gas reservoir, and results show that the fracture space has a measurable influence on migration of adsorbed gas. The fracture network can contribute to enhancement of the absorbed gas recovery ratio when the fracture space is less than $0.2 \mathrm{~m}$. ESRV is evaluated in this paper, and results indicate that the ESRV accounts for $27.87 \%$ of the total SRV in shale gas reservoirs. This work is important and timely for evaluating fracturing effect and predicting production of hydraulic fracturing wells in shale reservoirs.

Keywords: Fractal Geometry; Fracture Network; Effective Stimulated Reservoir Volume; Evaluation Approach; Shale Gas Reservoir.

\section{INTRODUCTION}

Justifying gas production in shale reservoirs is difficult because their extremely low permeability (in the range of nano-Darcy) and poorly connected natural fractures ${ }^{112}$ In order to maximize the contact area available for flow and produce shale gas effectively, horizontal drilling and hydraulic fracturing are widely employed $\stackrel{3-6}{-6}$ These hydraulic-fracturing practices not only create hydraulic fractures (HFs) with high conductivity but also connect preexisting natural fractures so as to generate a complex fracture network surrounding the hydraulic fractures.78 The region containing complex fracture networks is called stimulated reservoir volume (SRV) which largely enhances the original formation's permeability and governs dominant flow rates to the well. With respect to the 20-year estimated ultimate recovery, the contribution from the unstimulated reservoir volume is negligible when compared with that of the SRV 911

The SRV can be calculated by microseismic imaging, induced-fracture-monitoring technology and mathematical models based on fracture propagation regularity. 1218 However, the SRV calculated by conventional methods differs greatly difference from the effective SRV (ESRV) estimated by flowperformance curves or actual field production. $\underline{6}[19 \sqrt{20}$ Compared with SRV, ESRV is a more important prerequisite for confirming the success of hydraulic fracturing and predicting the production of hydraulic-fracturing wells in shale reservoirs. ESRV has become more and more valued by petroleum industry, even though there is no effective way of calculating ESRV. Conventional methods state that $\mathrm{SRV}$ is the area in which the preexisting natural fractures are connected. But in shale reservoirs, flow capability in unstimulated matrix is limited by extremely low permeability, 21 and gas in the large, unstimulated matrix of the SRV remains in the pore and throat space. To calculate ESRV then, we must consider not only extending rules of fracture networks, but also the flow capability in unstimulated matrix.

Recent publications show that natural fractures in rock have fractal characteristics, which influence liquid/gas flow and secondary fracture propagation. $22 \mid 23$ In addition, the heterogeneity of reservoir layers have created and the in situ stress field in particular, a complex fracture network. ${ }^{24[25}$ In order to stimulate the fracture geometry, therefore unconventional fracture model was developed. 2627 This model details propagation of the main fracture and its branches within an unstructured grid, which couples the stress field, orientation of the natural fractures (NFs) and rock deformation. In contrast, the wire-mesh mode 28$] 30$ utilizes two orthogonal sets of planar elements to represent the area of the fracture network or the SRV which is a simple but effective method of fracture modeling?27 And yet, these models do not represent the actual situation in the reservoir, but instead idealize the fracture network based on theories and assumptions. The distribution of fracture networks in SRV is sometimes monitored by the microseismic cloud 


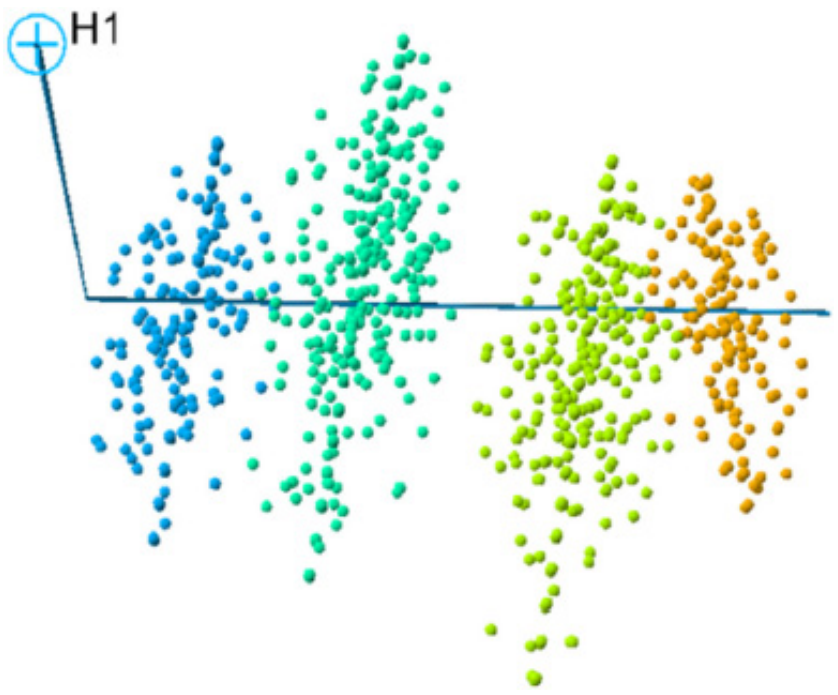

Fig. 1 Micro-seismic data of fractured horizontal well with complex fracture networks. ${ }^{37}$ Dots with different colors represent lateral extension of four fracturing stages.

(Fig. 1). Researches has shown that the fracture network surrounding the HFs is not irregular, but can be regressed using different types of fractal theoretical models. ${ }^{[31] \sqrt[36]]{3}}$ Zhou et al..$^{[37,38}$ proposed a method based on the L-system (Lindenmayer system), in which The fracture geometry is calibrated by the matching of microseismic data with an Lsystem based on fractal-geometry theory. However, the density of induced fractures generated by Zhou's method increases the farther away they are from the well, which is not reasonable for horizontal wells.

In this paper, a fractal random-fracture-network algorithm (FRFNA) is proposed to quantitatively characterize fracture-networks propagation regularity, and a multi-porosity REV flow model is presented as a criterion for adsorbed gas fully mobilized. A new ESRV calculation approach is proposed by combining the ESRV criterion and fractal characteristics of the fracture network. The approach has been used in the Eagle Ford shale gas reservoir to evaluate its ESRV.

\section{FRACTAL GEOMETRY OF FRACTURE NETWORK}

In this part, we match the nodes of a fractal-fracture network to microseismic data so as to calibrate the fracture geometry using the integer programming 37 39] Fracture networks are recovered from a perspective of fractal geometry by converting the matching issue to a $0-1$ programming problem. Zhou et al ${ }^{39}$ detailed four controlling influence of each parameter of the fractal-fracture network. These four key parameters relate closely with the fractal-fracture geometry, which might influence the performance of the SRV: (1) generating length $(d)$ depends the length of main fracture and its branches (2) deviation angle $(\alpha)$ controls orientation when a fracture deviates or generates a secondary branch (3) iteration times $(N)$ control the extension of the fractal fracture according to the growth of the fractal tree, and (4) generating rules control the growth of bifurcation.

\subsection{Fractal Random-Fracture- Network Algorithm}

On the basis of Zhou's method, $\frac{37 / 38}{\sqrt{3}}$ this paper introduce a random function for modifying generating rules that are based on microseismic data and the induced-fracture-network heel. Forward bifurcation (density of fractures increases the farther away they are from the induced-fracture-network heel) and reverse bifurcation (density of fractures decreases the farther away they are from the induced-fracturenetwork heel) are chosen, according to the location of the induced-fracture-network heel and the distribution of microseismic data. The matching model for FRFNA is as follows:

$$
\begin{array}{ll}
\text { Obj : } & \min =\sum_{i=1}^{m} \sum_{j=1}^{n} p_{i j} l_{i j}, \\
\text { S.T. } & \left\{\begin{array}{l}
\sum_{j=1}^{m} p_{i j}=1 \\
l_{i j} \leq \xi \\
\sum_{i=1}^{m} \sum_{j=1}^{n} p_{i j}=n
\end{array}\right.
\end{array}
$$

$$
p i j=\left\{\begin{array}{c}
1 i \text { th micro-seismic data couple with } \\
j \text { th fractal node } \\
0 i \text { th micro-seismic data do not } \\
\quad \text { couple with } j \text { th fractal node }
\end{array},\right.
$$

where $m$ is the number of microseismic data and $n$ is the number of fracture nodes; $i$ and $j$ are their serial numbers. $p_{i j}$ is binary and $l_{i j}$ is a variable that represents the distance between the $i$ th microseismic data and the $j$ th fracture node.

In the proposed FRFNA, a new parameter, matching rate $(f)$, is introduced to evaluate the 


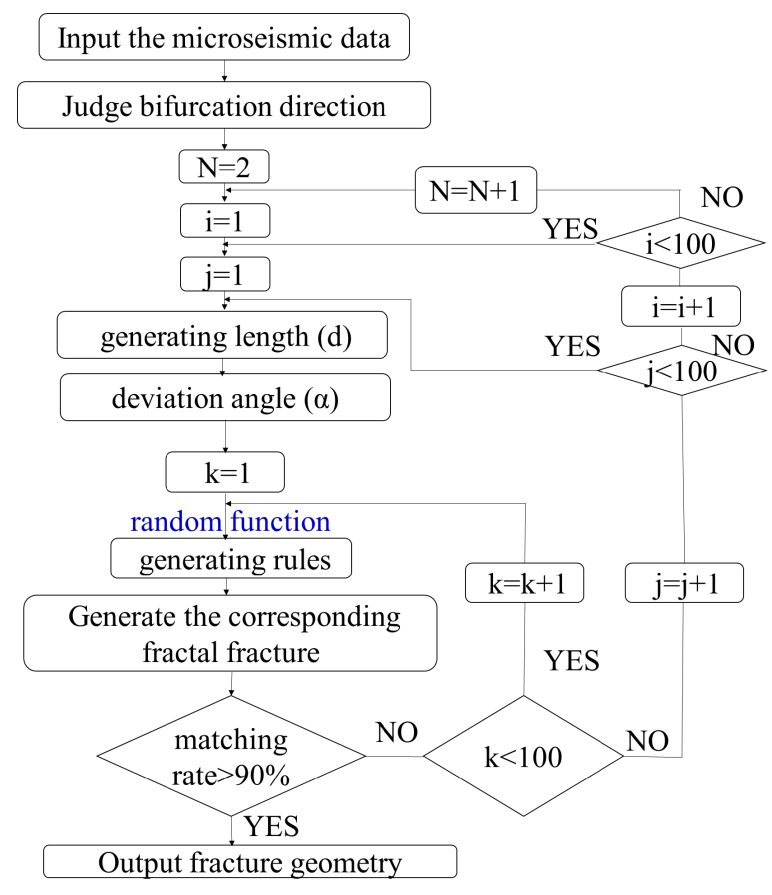

Fig. 2 Workflow of FRFNA.

fitting effect. The matching rate is defined as:

$$
f=\frac{\sum_{i=1}^{m} d_{i}}{\sum_{i=1}^{m} d_{i 0}}
$$

where $d_{i}$ is the distance between $i$ th microseismic data and the nearest fracture node $m$ and $d_{i 0}$ is the distance between $i$ th microseismic data and the nearest fracture heel $m$.

The workflow for FRFNA (Fig. 2) has 12 detailed steps: (1) input the microseismic data and extract the coordinate in Matlab and (2) judge the bifurcation direction according to the distribution characteristics of fractures density (forward or reverse bifurcation). In this step, forward-bifurcation tree-generating rules or reverse-bifurcation treegenerating rules will be determined, (3) propose iteration times to control the extension of the fractal fracture. In general, we assign initial iteration times the value of 2, (4) propose an approximate range of generating length according to the distribution of microseismic data. Divide the range into 100 parts. Set initial loop variable for generating length $(i)$ to $1,(5)$ propose an approximate range of deviation angle according to the distribution of microseismic data. Divide the range into 100 parts, and set the initial loop variable for deviation angle $(j)$ to $1,(6)$ set loop the variable for generating rules $(k)$ to $1,(7)$ introduce the random function to determine specific generating rules, (8) generate the corresponding fractal geometry by combining iteration times, generating length, deviation angle and specific generating rules, (9) sum the distance between every microseismic datum and the nearest fracture node, and the distance between every microseismic datum and the nearest fracture heel. If the matching rate is larger than the given criterion (in this paper, the criterion is $90 \%$ ), then we think that this fracture geometry will perfectly fit the microseismic data and outputs this fracture geometry. When the matching rate is smaller than the given criterion, if loop variable for generating rules $(k)$ is smaller than 100 , then add one to $k$ and repeat step. Otherwise, move on to the next step, (10) add one to the loop variable for the deviation angle $(j)$. If $j$ is smaller than 100, repeat step 5 . If not, move on to the next step, (11) add one to the loop variable for the generating length $(j)$. If $i$ is smaller than 100, repeat step 4, if not, move on to the next step and (12) add 1 for initial iteration times, repeat step 3.

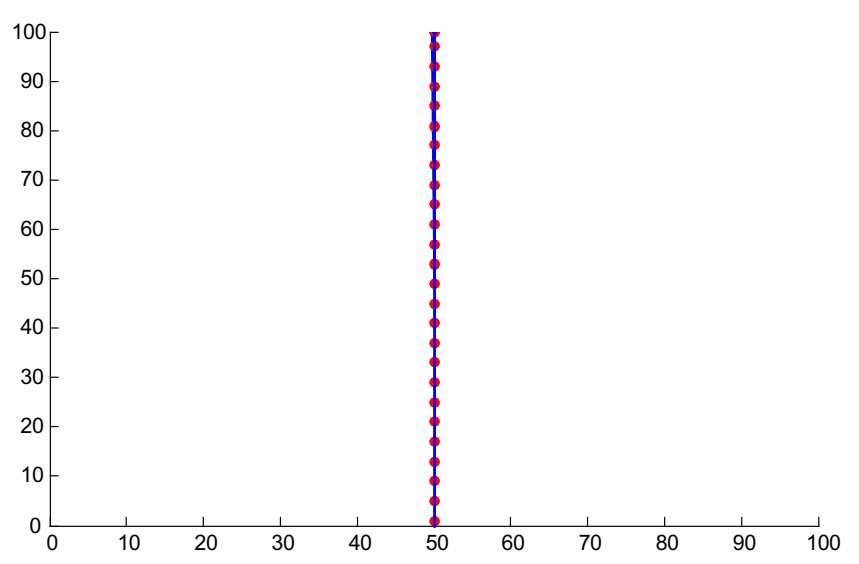

Fig. 3 Single fracture generated by FRFNA.

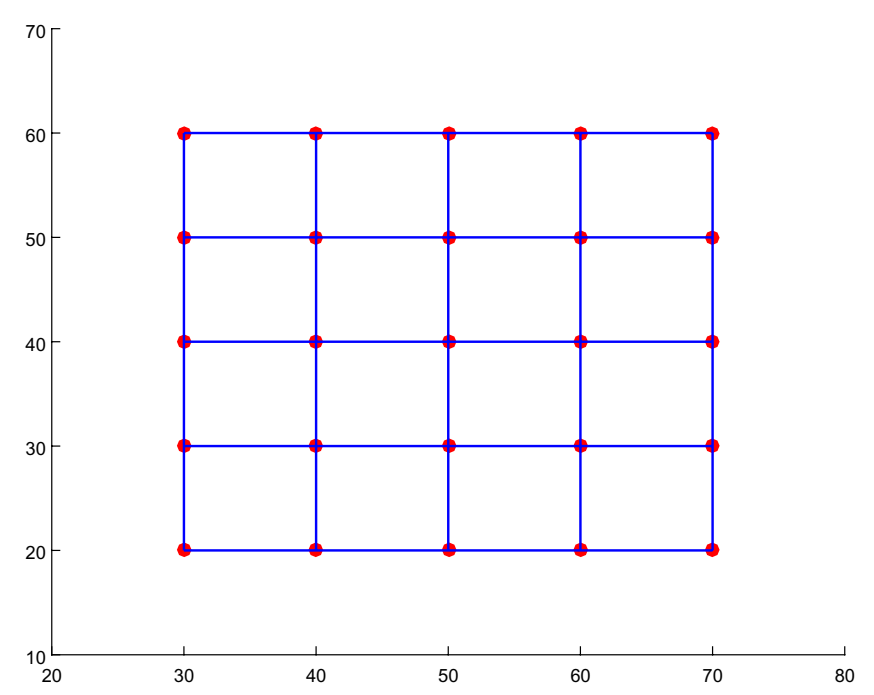

Fig. 4 Orthogonal fractures generated by FRFNA. 


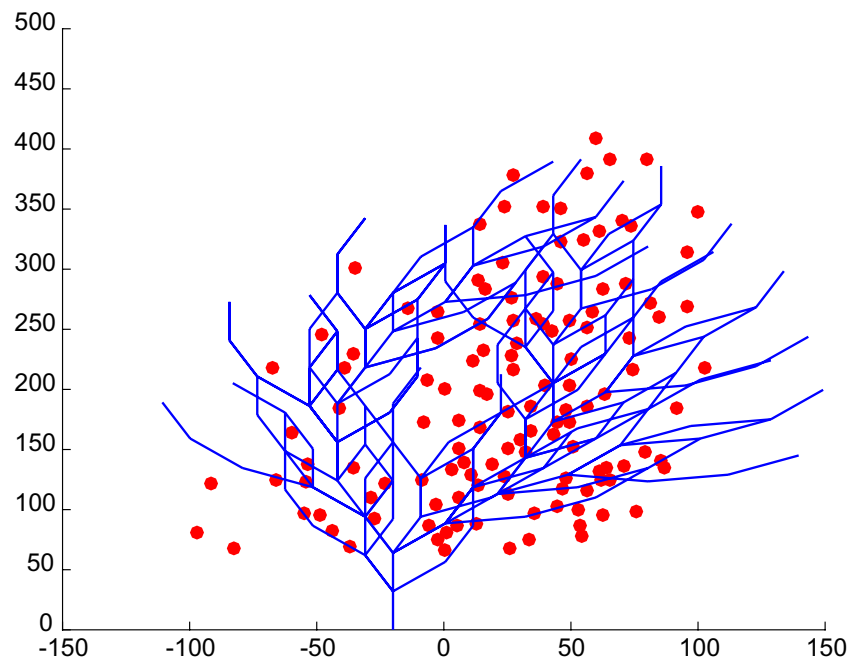

(a)

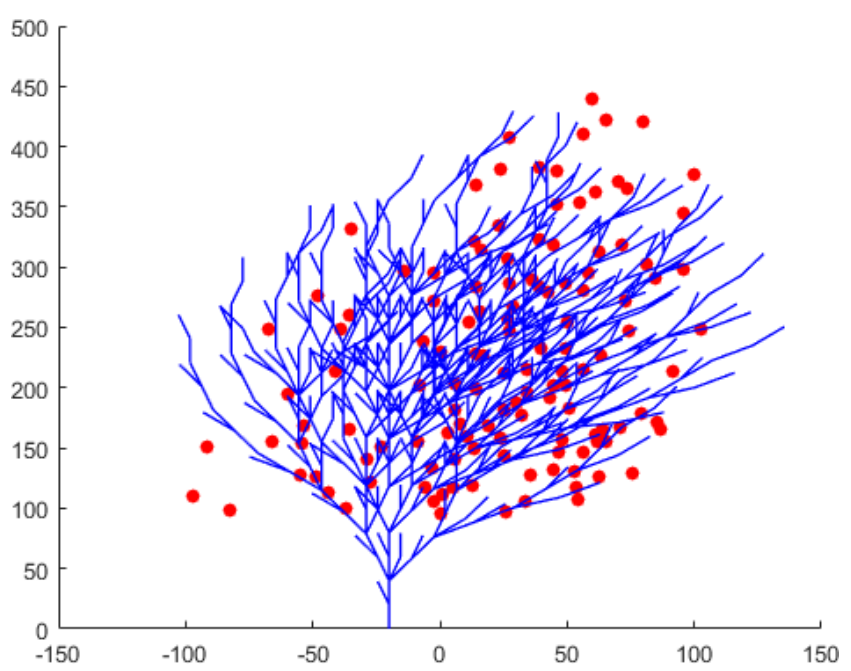

(b)

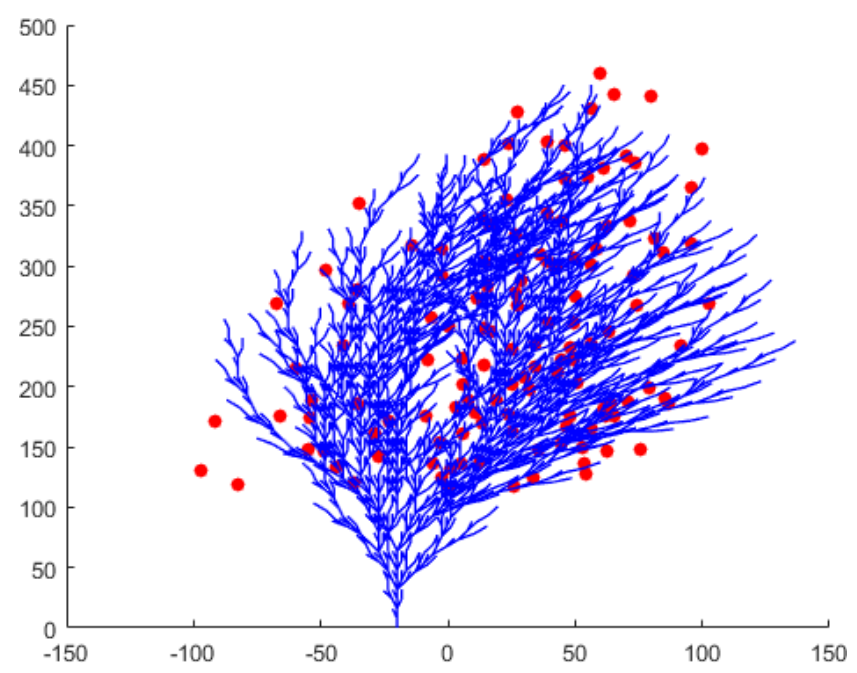

(c)

Fig. 5 Complex fracture network generated by FRFNA.

\subsection{Fractal-Fracture Geometry}

Figures 3 , show three fractal-fracture geometries generated by FRFNA. Table 1 presents the main parameters of fracture geometry. Accordinf to these figures, we know that fractures generated by FRFNA fit well with the microseismic data. Fractal geometry is applicable not only to simple fractures, such as a single-fracture (Fig. 31) and orthogonal fractures (Fig. 5), but also to a complex fracture network (Fig. 5). Iteration times greatly influence fractal geometry and matching rate. Figure 5 presents three different fracture geometries generate from the same microseismic data, respectively. Note that as the iteration times increase, the number of secondary fractures shows a geometric growth and the matching rate also increases. When the geometry iterative five times, the microseismic data will generate 6125 secondary fractures and the matching rate is more than $90 \%$. Showing that fractures generated by FRFNA are becoming more similar to the actual fracture networks in reservoirs. The table also shows that the number of fracture nodes is higher than the number of microseismic data, which is reasonable for oil/gas reservoirs because microseismic can monitor only main fractures in the SRV region. It is worth noting that large matching rate does not always equate with accurate result. We must evaluate it within the SRV region because large iteration times will generate a large range of fracture geometries. Fracture network geometry must be located within the SRV range. 
Table 1 Parameters of Fractures Generated by FRFNA.

\begin{tabular}{|c|c|c|c|c|c|}
\hline \multirow[t]{2}{*}{ Bifurcation Direction } & \multirow{2}{*}{$\frac{\text { Single Fracture }}{\text { Forward Bifurcation }}$} & \multirow{2}{*}{$\frac{\text { Orthogonal Fractures }}{\text { Reverse Bifurcation }}$} & \multicolumn{3}{|c|}{ Complex Fracture Network } \\
\hline & & & \multicolumn{3}{|c|}{ Forward Bifurcation } \\
\hline Number of Microseismic Data $(m)$ & 26 & 25 & \multicolumn{3}{|c|}{128} \\
\hline Number of fracture nodes $(n)$ & 7 & 784 & 245 & 1225 & 6125 \\
\hline Iteration times $(N)$ & 2 & 3 & 3 & 4 & 5 \\
\hline Matching rate $(f) / \%$ & 100 & 99.99 & 81.49 & 86.60 & 91.50 \\
\hline
\end{tabular}

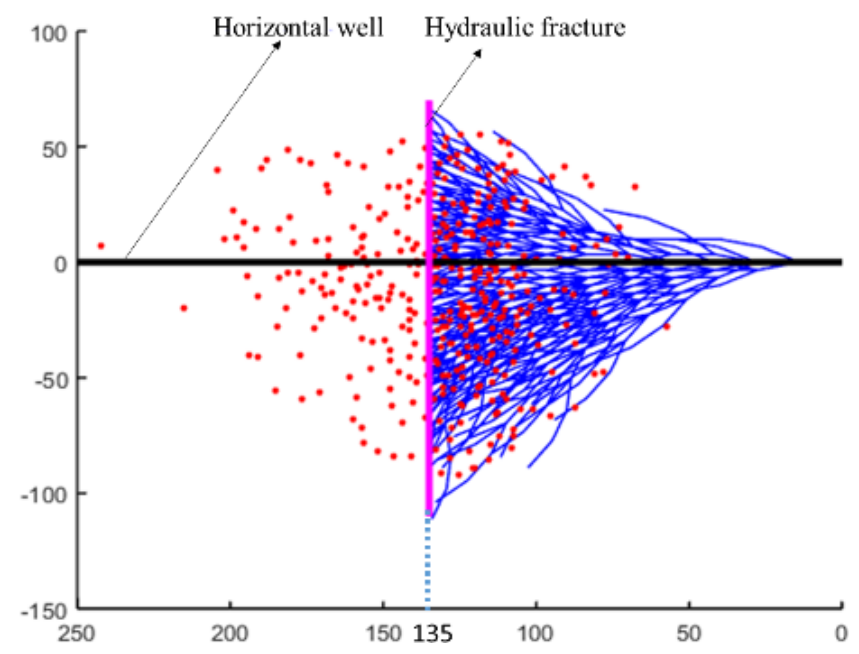

Fig. 6 Fracture network generated by FRFNA for horizontal well in Eagle Ford $(N=6, m=249, n=4900$, $f=89.40 \%$ ).

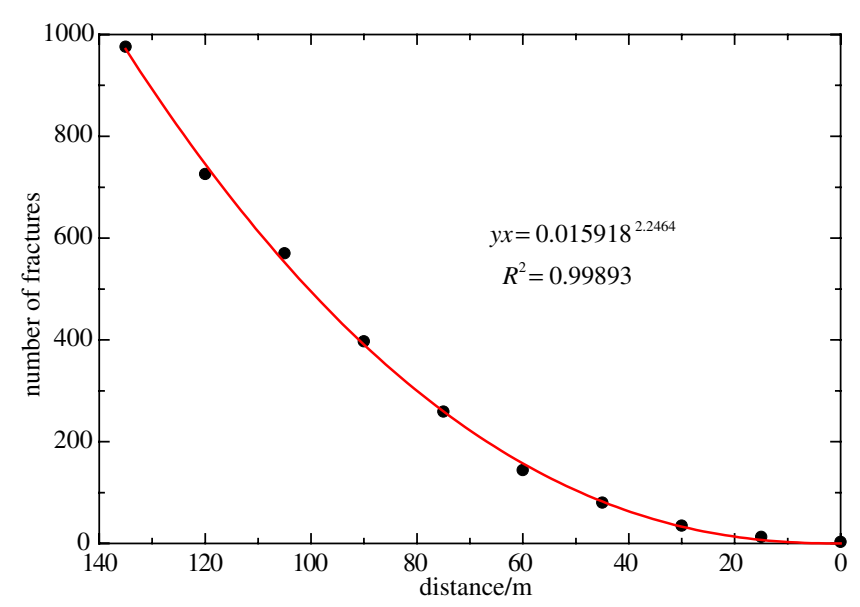

Fig. 7 Distribution of induced fractures for SRV in Eagle Ford $(N=7, m=249, n=24500, f=98.70 \%)$.

\subsection{Actual Field Example of FRFNA}

The FRFNA was used in the Eagle Ford shale reservoir to calculate the microseismic data in a multistage fractured horizontal well. Corresponding fractal-fracture geometry was output, as shown in Fig. 6. The fracture network extends from one HF to the middle position of two HFs. Therefore, the multi-stage fractured horizontal well is thought to have fracture-network geometry with typical reverse bifurcation. Figure 6] shows that the density of induced fractures in the SRV decreases the farther away the location is from HF. Quantitative distribution characteristics of induced fractures for SRV in fractal-fracture geometry was also calculated by FRFNA (Fig. 7), the number of fractures being represented by Eq. (5). The distribution of induced fractures for SRV calculated by FRFNA agrees with many scholars' research.1012140

$$
f \_n=0.015918 x^{2.2464} \text {. }
$$

\section{ESRV CRITERION FOR SHALE GAS RESERVOIRS}

\subsection{Mathematical REV Model}

According to our previous research, $\frac{41}{4}$ the SRV region is composed of porous kerogen, inorganic matrix and fracture networks (as shown in Fig. 8). From the figure, we can get that the porous kerogen and inorganic matrix are randomly distributed in shale gas reservoirs, whereas the fracture network, although not irregular can be quantitatively characterized by fracture geometry. Considering the reservoir characteristics in the SRV region, we can make some assumptions. $\stackrel{41}{ }$ the porous kerogen and inorganic matrix are evenly distributed in shale gas reservoirs, and the fractal-fracture geometry is in the same magnitude and the fracture space increases as location is farther away from the HF. Because the flow capability in porous kerogen and inorganic matrix is limited by extremely low permeability, ture space remains in the pore and throat space. On the basis of these assumptions, we introduced an orthogonal-fracture coupled dual-porosity-media 


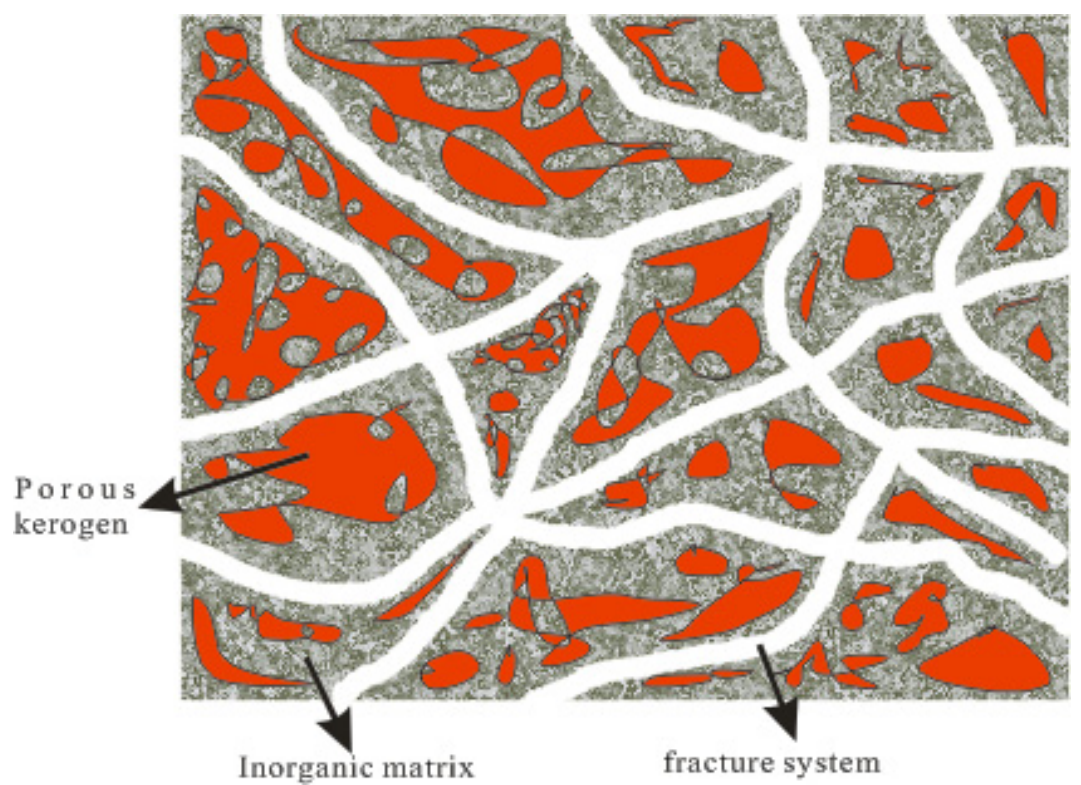

Fig. 8 Distribution of multi-scaled pore media in the SRV area of shale gas reservoir!41
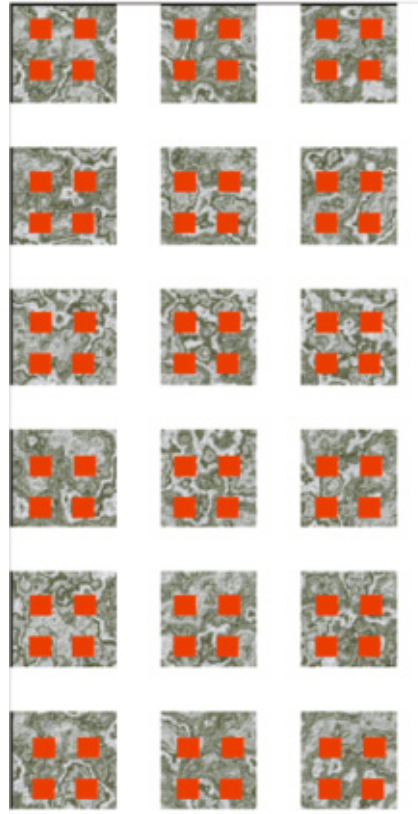
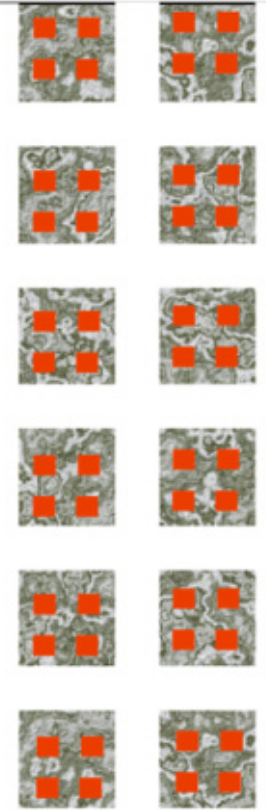
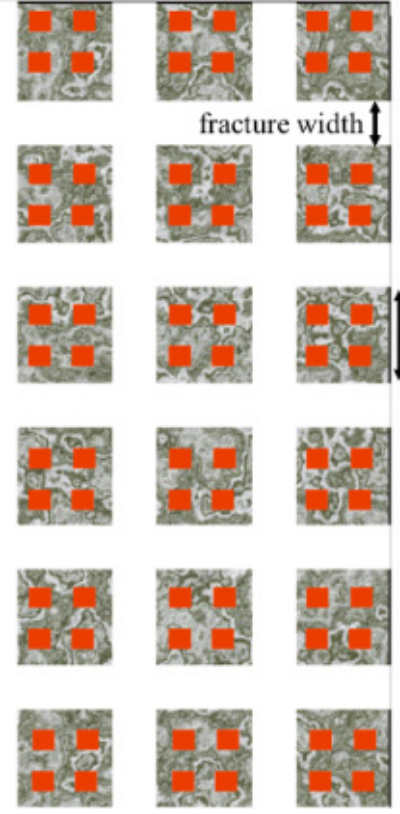

Fig. 9 A representative elementary volume in the SRV area.

REV flow model for a small area (as shown in Fig. 9). In this REV model, the secondary fractures were considered orthogonal distribution, with the same fracture spacing in a very small area of the SRV. The matrix block was composed of evenly distributed porous kerogen and inorganic matrix and was cut into cubes by secondary fractures and evenly distributed in the REV model. Shale gas was stored in porous kerogen and diffused from porous kerogen to exposed surfaces and inorganic matrix.
Shale gas transport mechanisms in the SRV include flow in the porous kerogen (Knudsen diffusion and viscous flow of free gas and surface diffusion of absorbed gas), cross-flow from porous kerogen to the inorganic matrix, flow in the inorganic matrix (Knudsen diffusion and viscous flow of free gas), cross-flow from the inorganic matrix to the fracture networks and flow in the fracture networks (viscous flow of free gas) 4147 The mathematical REV model is presented in the following equations. 
G. Sheng et al.

Free gas in porous kerogen:

$$
\begin{aligned}
& \frac{\partial\left(\phi_{k}\left(p_{k} / Z R T\right)\right)}{\partial t} \\
& =\left(\frac{p_{k}}{Z R T}\left(1+\sqrt{\frac{8 \pi R T}{M}} \frac{\mu_{g}}{p_{k} r_{k}}\left(\frac{2}{f}-1\right)\right)\right. \\
& \quad \times \frac{\left(\phi_{k} / \tau_{k}\right)\left(r_{k}^{2} / 8\right)}{\mu_{g}} \\
& \left.\quad+\frac{\phi_{k}}{\tau_{k}} \frac{2 r_{k}}{3} \sqrt{\frac{8 Z R T}{\pi M}} \frac{p_{k}}{Z R T} C_{g}\right) \nabla p_{k}
\end{aligned}
$$

where $p_{k}$ is the kerogen pressure in $\mathrm{MPa} ; Z$ the gas compressibility factor; $R$ the universal gas constant, $8.314 \times 10^{-6} \frac{\mathrm{MJ}}{\mathrm{K}} \mathrm{mol} ; T$ the formation temperature in $\mathrm{K} ; M$ the molecular mass of shale gas in $\mathrm{kg} / \mathrm{mol}$; $\mu_{g}$ the gas viscosity in $\mathrm{mPa} s ; r_{k}$ the pore size in kerogen in $\mathrm{m} ; f$ the fraction of molecules striking pore wall which are diffusely reflected; $\phi_{k}$ the kerogen porosity; $\tau_{k}$ the tortuosity-corrected of pore in kerogen and $C_{\mathrm{g}}$ the gas compressibility in $\mathrm{MPa}^{-1}$.

Absorbed gas in porous kerogen:

$\frac{\partial\left(\varepsilon_{k s}\left(1-\phi_{k}\right) c_{\mu}\right)}{\partial t}=\varepsilon_{k s}\left(1-\phi_{k}\right) D_{s} \frac{c_{\mu s} p_{k}}{\left(p_{L}+p_{k}\right)^{2}} \nabla p_{k}$,

where $c_{\mu}$ is the moles of adsorbed gas per solid volume of kerogen in $\mathrm{mol} / \mathrm{m}^{3} ; \varepsilon_{k s}$ the proportion of solid kerogen volume in the total interconnected matrix pore volume; $D_{s}$ the surface diffusion coefficient in $\mathrm{m}^{2} / \mathrm{s} ; c_{\mu \mathrm{s}}$ the Langmuir volume on the kerogen surface in $\mathrm{mol} / \mathrm{m}^{3}$ and $p_{L}$ is the Langmuir's pressure in MPa.

Free gas in inorganic matrix:

$$
\begin{aligned}
& \frac{\partial\left(\phi_{m}\left(p_{m} / Z R T\right)\right)}{\partial t}\left(\frac{\phi_{m}}{\tau_{m}} \frac{2 r_{m}}{3} \sqrt{\frac{8 Z R T}{\pi M}} \frac{p_{m}}{Z R T} C_{g}+\frac{p_{m}}{Z R T}\right. \\
& \quad \times\left(1+\sqrt{\frac{8 \pi R T}{M}} \frac{\mu_{g}}{p_{m} r_{m}}\left(\frac{2}{f}-1\right)\right) \\
&\left.\quad \times \frac{\left(\phi_{m} / \tau_{m}\right)\left(r_{m}^{2} / 8\right)}{\mu_{g}}\right) \nabla p_{m},
\end{aligned}
$$

where $\phi_{m}$ is the inorganic matrix porosity; $\tau_{m}$ the tortuosity-corrected of pore in inorganic matrix; $r_{m}$ the pore size in inorganic matrix in $\mathrm{m}$ and $p_{m}$ the inorganic matrix pressure in MPa.
Free gas in fracture:

$$
\frac{\partial\left(\phi_{f}\left(p_{f} / Z R T\right)\right)}{\partial t}=\frac{p_{f}}{\mu_{g} Z R T} \frac{f w^{2}}{8} \nabla p_{f},
$$

where $\phi_{f}$ is the fracture system porosity; $p_{f}$ the fracture system pressure in MPa and $f w$ the width of fracture in $\mathrm{m}$.

Mass transfer from porous kerogen to inorganic matrix:

$$
N_{k m}=\sigma_{k} \frac{p_{k}}{Z R T} \frac{k_{k}}{\mu_{g}}\left(p_{k}-p_{m}\right),
$$

where $N_{k m}$ is the transfer term between porous kerogen and the inorganic matrix in $\mathrm{mol} /\left(\mathrm{m}^{3} \mathrm{~s}\right)$; $\sigma_{k}$ the pseudo-steady-state shape factor for porous kerogen in $1 / \mathrm{m}^{2}$ and $k_{k}$ the apparent permeability of porous kerogen in $\mathrm{mD}: 41$

$$
\begin{aligned}
k_{k}= & \frac{\phi_{k}}{\tau_{k}} \frac{2 r_{k}}{3} \sqrt{\frac{8 Z R T}{\pi M}} C_{g} \mu_{g}+\varepsilon_{k s}\left(1-\phi_{k}\right) D_{s} \\
& \times \frac{c_{\mu s} Z R T}{\left(p_{L}+p_{k}\right)^{2}} \mu_{g} \\
& +\left(1+\sqrt{\frac{8 \pi R T}{M}} \frac{\mu_{g}}{p_{k} r_{k}}\left(\frac{2}{f}-1\right)\right) \frac{\phi_{k}}{\tau_{k}} \frac{r_{k}^{2}}{8} .
\end{aligned}
$$

\subsection{Solutions of the REV Model}

Suppose a pressure difference were to exit between the left and right boundaries, and gas were to escape from the right boundary. Unstructured mesh grids could then be generated and solved using the finite element method in the REV model. For the matrix block, the inorganic matrix pressure $p_{\mathrm{m}}$ and porous kerogen pressure $p_{\mathrm{k}}$ could be alternately solved using Eqs. (6) -(8) and (10). The time domain is discretized by forward difference; we can solve for the inorganic matrix pressure at $n+1$ step:

$$
\begin{aligned}
\frac{\phi_{m}}{Z R T} \frac{p_{m}^{n+1}-p_{m}^{n}}{t^{n+1}-t^{n+1}} & =\frac{p_{m}^{n}}{\mu_{g} Z R T} k_{m} \nabla p_{m}^{n+1}+N_{k m}^{n+1}, \\
N_{k m}^{n+1} & =\sigma_{k} \frac{p_{k}^{n}}{Z R T} \frac{k_{k}}{\mu_{g}}\left(p_{k}^{n}-p_{m}^{n}\right)
\end{aligned}
$$

where

$$
\begin{aligned}
k_{m}= & \frac{\phi_{m}}{\tau_{m}} \frac{2 r_{m}}{3} \sqrt{\frac{8 Z R T}{\pi M}} C_{g} \mu_{g} \\
& +\left(1+\sqrt{\frac{8 \pi R T}{M}} \frac{\mu_{g}}{p_{m} r_{m}}\left(\frac{2}{f}-1\right)\right) \frac{\phi_{m}}{\tau_{m}} \frac{r_{m}^{2}}{8} .
\end{aligned}
$$


Assuming that the entire REV nodes number is $N_{p}$, pressure of the inorganic matrix can be written as:

$$
p_{m} \approx \sum_{i=1}^{3} N_{i} P_{m i}=N_{e} P_{m e},
$$

where $N_{e}$ is the shape function of the REV element, $N_{e}=\left[N_{1}, N_{2}, N_{3}\right]$ and $P_{\mathrm{m}_{e}}$ is the node pressure of inorganic matrix, $P_{m e}=\left[p_{m 1}, p_{m 2}, p_{m 3}\right]$.

Integrating over Eq. (12) with Gauss part integral formula, we can get

$$
R_{m} \frac{P_{m}^{n+1}-P_{m}^{n}}{t^{n+1}-t^{n+1}}=A_{m} P_{m}^{n+1}+Q_{m}^{n+1},
$$

where

$$
\begin{aligned}
& P_{m e^{\prime}}=\left[\frac{1}{3} \frac{1}{3} \frac{1}{3}\right] P_{m e} ; \\
& \nabla N_{e}=\left[\begin{array}{lll}
\frac{\partial N_{1}}{\partial x} & \frac{\partial N_{2}}{\partial x} & \frac{\partial N_{3}}{\partial x} \\
\frac{\partial N_{1}}{\partial y} & \frac{\partial N_{2}}{\partial y} & \frac{\partial N_{3}}{\partial y}
\end{array}\right] ; \\
& A_{m}=\iint_{\Omega e} \nabla N_{e}^{T} \frac{P_{m e^{\prime}}^{n}}{\mu_{g} Z R T} k_{m} \nabla N_{e} d \Omega e ; \\
& R_{m}=\frac{\phi_{m}}{Z R T} \iint_{\Omega e} \nabla N_{e}^{T} N_{e} d \Omega e ; \\
& Q_{m}^{n+1}=\iint_{\Omega e} N_{e}^{T} N_{k m}^{n+1} d \Omega e ; \\
& P_{m}=\left[p_{m 1}, p_{m 2}, \ldots, p_{m N_{p}}\right]^{T} .
\end{aligned}
$$

The govern equation of the finite element for the inorganic matrix can be written as:

$$
\begin{aligned}
\left(A_{m}\right. & \left.-\frac{R_{m}}{t^{n+1}-t^{n+1}}\right) P_{m}^{n+1} \\
& \quad+\frac{R_{m}}{t^{n+1}-t^{n+1}} P_{m}^{n}+Q_{m}^{n+1}=0 .
\end{aligned}
$$

In the same way, we get governing equations for porous kerogen and fractures as follows:

$$
\begin{aligned}
& \left(A_{k}-\frac{R_{k}}{t^{n+1}-t^{n+1}}\right) P_{k}^{n+1} \\
& \quad+\frac{R_{k}}{t^{n+1}-t^{n+1}} P_{k}^{n}-Q_{m}^{n+1}=0, \\
& \left(A_{f}-\frac{R_{f}}{t^{n+1}-t^{n+1}}\right) P_{f}^{n+1} \\
& \quad+\frac{R_{f}}{t^{n+1}-t^{n+1}} P_{f}^{n}=0,
\end{aligned}
$$

where

$$
\begin{aligned}
R_{k}= & \frac{\phi_{k}+\varepsilon_{k s}\left(1-\phi_{k}\right) c_{\mu s}\left(Z R T / p_{L}+p_{k}\right)}{Z R T} \\
& \times \iint_{\Omega e} \nabla N_{e}^{T} N_{e} d \Omega e ; \\
P_{k e}= & {\left[p_{k 1}, p_{k 2}, p_{k 3}\right] } \\
A_{m}= & \iint_{\Omega e} \nabla N_{e}^{T} \frac{P_{k e^{\prime}}^{n}}{\mu_{g} Z R T} k_{k} \nabla N_{e} d \Omega e ; \\
P_{k e^{\prime}}= & {\left[\frac{1}{3} \frac{1}{3} \frac{1}{3}\right] P_{k e} ; \quad P_{k}=\left[p_{k 1}, p_{k 2}, \ldots, p_{k N_{p}}\right]^{T} } \\
R_{f}= & \frac{\phi_{f}}{Z R T} \iint_{\Omega e} \nabla N_{e}^{T} N_{e} d \Omega e ; \\
P_{f e}= & {\left[p_{f 1}, p_{f 2}, p_{f 3}\right] } \\
A_{f}= & \iint_{\Omega e} \nabla N_{e}^{T} \frac{P_{f e^{\prime}}^{n}}{\mu_{g} Z R T} \frac{f w^{2}}{8} \nabla N_{e} d \Omega e ; \\
P_{f e^{\prime}}= & {\left[\frac{1}{3} \frac{1}{3} \frac{1}{3}\right] P_{f e} ; \quad P_{f}=\left[p_{f 1}, p_{f 2}, \ldots, p_{f N_{p}}\right]^{T} . }
\end{aligned}
$$

If the boundary condition, the pressure in porous kerogen, inorganic matrix and fractures are combined, the absorbed gas recovery ratio (AGRR) in porous kerogen can be obtained by alternately solving Eqs. (16)-(18). Finally, we analyzed the effect of fracture space on gas migration using parameters for the Eagle Ford well (as shown in Table 2).

Absorbed gas in porous kerogen has more flow difficultly than does free gas in porous kerogen and inorganic matrix. So the AGRR must therefore be used as a key parameter to judge whether a region with a certain fracture space is ESRV. AGRR in porous kerogen of REV with different fracture spaces was calculated, and the effect of fracture space on AGRR was analyzed (Fig. 10). Figure 10a shows that gas stored in the region near fracture is fully produced, and gas in the middle of unstimulated matrix remains in pore and throat space. Figure 10b indicates that fracture space has a great influence on AGRR, and the smaller the fracture space, the more the absorbed gas produced. Figure 10k indicates that adsorbed gas in porous kerogen can escape from the pore and throat space of unstimulated matrix more and more when the fracture space is $<0.2 \mathrm{~m}$. We therefore conclude that for the Eagle Ford well, when the fracture space is $<0.2 \mathrm{~m}$ in the SRV, the fracture network will contribute by enhancing AGRR. In other words, any region whose fracture space is $<0.2 \mathrm{~m}$ is the ESRV for this Eagle Ford well. 
Table 2 Parameters of Shale Reservoirs.

\begin{tabular}{|c|c|c|c|}
\hline Parameters & Value & Parameters & Value \\
\hline Fracture width $(\mathrm{m})$ & 0.005 & Pressure in left boundary (MPa) & 15 \\
\hline Reservoir thickness (m) & 19 & Pressure in right boundary $(\mathrm{MPa})$ & 15.1 \\
\hline Kerogen pore size (nm) & 50 & Kerogen porosity & 0.2 \\
\hline Inorganic-matrix porosity & 0.1 & Inorganic-matrix pore size $(\mathrm{nm})$ & 100 \\
\hline Number of fracture in horizontal direction & 10 & Fracture-network porosity & 0.001 \\
\hline Number of fracture in vertical direction & 10 & Fracture space $(\mathrm{m})$ & 0.05 \\
\hline Gas viscosity ( $\mathrm{mPa} \mathrm{s})$ & 0.0184 & Gas compressibility $\left(\mathrm{MPa}^{-1}\right)$ & $5 \mathrm{e}-2$ \\
\hline Molecular mass of shale gas $(\mathrm{kg} / \mathrm{mol})$ & 0.016 & Langmuir's pressure (MPa) & 13.78 \\
\hline Formation temperature $(\mathrm{K})$ & 338 & Shape factor of porous kerogen $\left(1 / \mathrm{m}^{2}\right)$ & 0.5 \\
\hline $\begin{array}{l}\text { Portion of the kerogen volume in the total } \\
\text { interconnected matrix pore volume }\end{array}$ & 0.5 & $\begin{array}{l}\text { Fraction of molecules striking pore wall } \\
\text { that are diffusively reflected }\end{array}$ & 0.8 \\
\hline Tortuosity-corrected of pore size in inorganic matrix & 5 & Tortuosity-corrected of pore size in kerogen media & 5 \\
\hline Langmuir volume on the kerogen surface $\left(\mathrm{m}^{3} / \mathrm{kg}\right)$ & $3.1 \mathrm{e}-3$ & Initial pressure of the shale gas reservoir (MPa) & 50 \\
\hline Surface diffusion coefficient $\left(\mathrm{m}^{2} / \mathrm{s}\right)$ & $5 \mathrm{e}-4$ & Gas compressibility factor & 0.5 \\
\hline
\end{tabular}

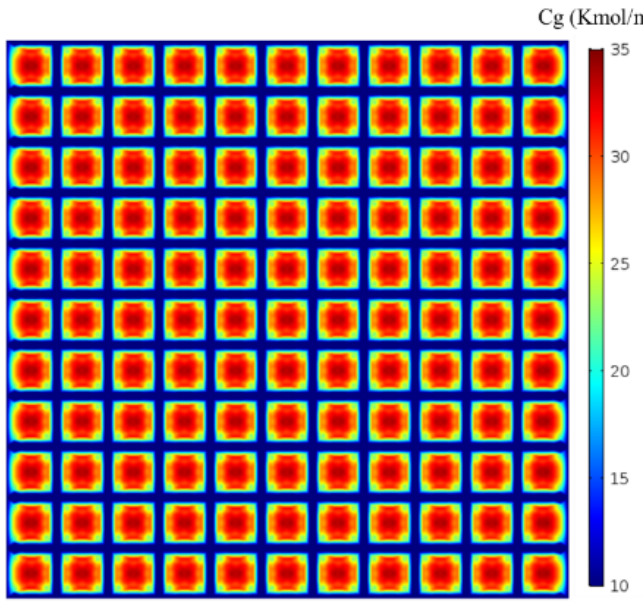

(a)

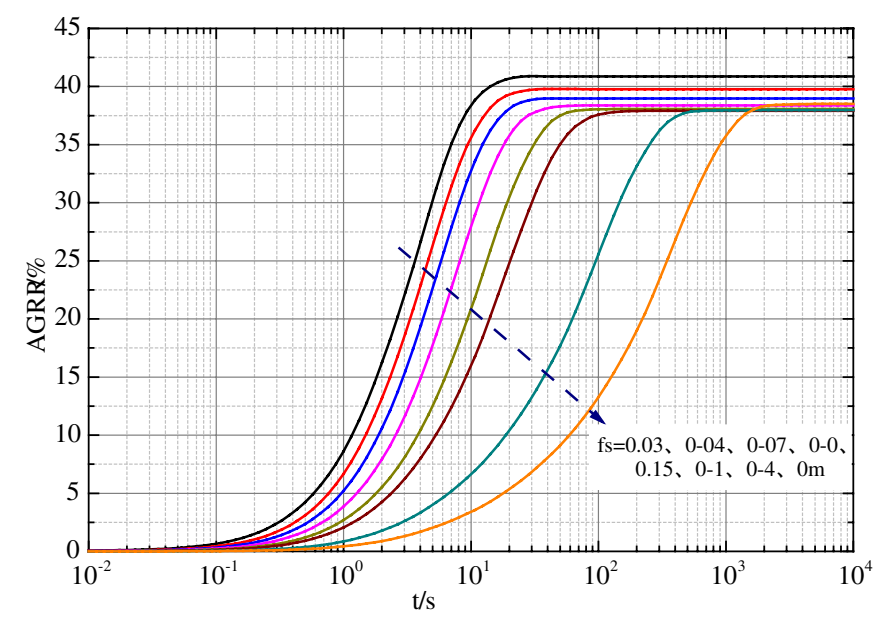

(b)

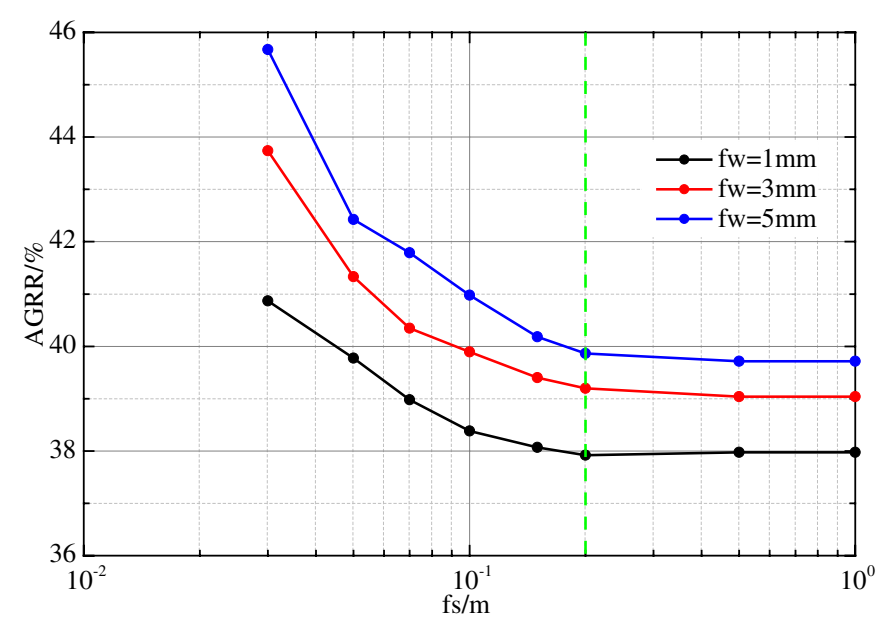

(c)

Fig. 10 Effect of fracture space on AGRR. 


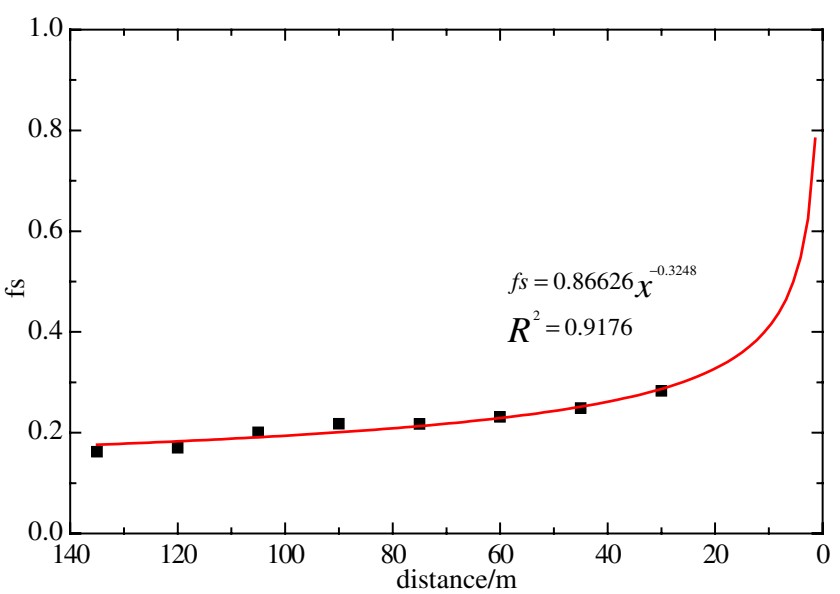

Fig. 11 Distribution of fracture space for SRV in Eagle Ford well.

\section{EVALUATION APPROACH OF ESRV}

The fractal-fracture geometry calculated by FRFNA is shown in Fig. [6] and the distribution characteristics of induced fractures for fractalfracture geometry are represented by Eq. (5). The induced-fracture space in the fracture network can thus be calculated by the following equation:

$$
f s=\frac{f \_n}{\text { width fracture network }} .
$$

We calculate the induced-fracture space in the fracture network (Fig. 11), and results show that the fracture space increases the farther away it is from the HF. The distribution of fracture space can be represented by the following equation:

$$
f s=0.86626 x^{-0.3248} \text {. }
$$

Using Eq. (13), we were able to calculate that the distance from the fracture network toe to the ESRV criterion position is $105 \mathrm{~m}$. Combining the ESRV criterion and fractal characteristic of the fracture network, we then calculated the ESRV of the Eagle Ford well (Fig. 12). Considering the thickness of the shale reservoir, we found that the ESRV for a single HF of the Eagle Ford well was $112.95 \times 10^{3} \mathrm{~m}^{3}$, whereas the SRV between HFs is $405.27 \times 10^{3} \mathrm{~m}^{3}$ and the volume of the region with microseismic data was $171.62 \times 10^{3} \mathrm{~m}^{3}$. The ESRV accounts for $27.87 \%$ of the total SRV in the Eagle Ford well. Figure 12 also indicates that the distribution of ESRV agrees with the concentrations of microseismic data. The ESRV accounts for $65.81 \%$ of the total volume of the region filled with microseismic data for the Eagle Ford well.

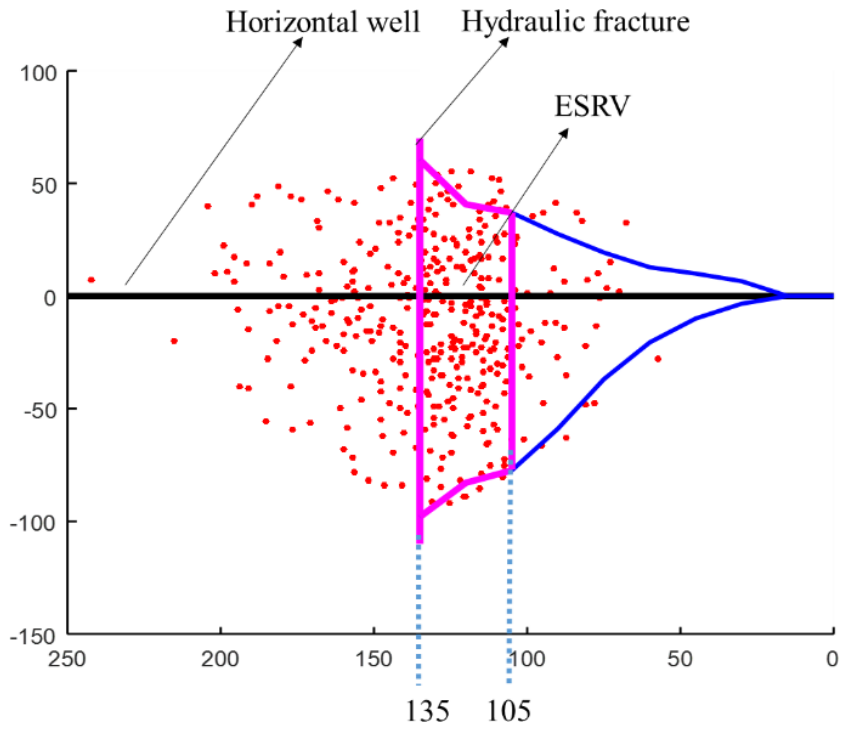

Fig. 12 Distribution of ESRV of Eagle Ford well.

\section{CONCLUSION}

This paper has introduced the application of fractal geometry to calculations of ESRV in a shale gas reservoir, as well as an FRFNA for converting microseismic data into fractal geometry for a multistage fractured horizontal well. Based on the migration of adsorbed gas in organic matter of REV with different fracture spaces, we have proposed an ESRV criterion for shale reservoirs along with a new approach for calculating the ESRV using fractal geometry. Major conclusions of this paper are as follows.

(1) An FRFNA was proposed to quantitatively characterize fracture networks propagation regularity. Results show that the fracture geometry generated by FRFNA agrees with actual fracture networks in reservoirs realized by microseismic. Fractal geometry is applicable not only to a single fracture and orthogonal fractures, but also to a complex fracture network.

(2) A fractal-fracture geometry was generated for a multistage fractured horizontal well in the Eagle Ford shale reservoir. Results show that the density of induced fractures in the SRV decreases the farther away from the HF it is. Power functions can be used to calculate the distribution of induced fractures precisely.

(3) An orthogonal-fracture coupled dual-porositymedia REV flow model was presented, and the effect of fracture space on gas migration was studied for the horizontal well in the Eagle Ford 
shale reservoir. Results show that fracture space has a great influence on AGRR. The smaller the fracture space, the larger the volume of absorbed gas produced. In the Eagle Ford well, ESRV is the region in which fracture space is $<0.2 \mathrm{~m}$.

(4) ESRV of the Eagle Ford well was evaluated, and results show that the distribution of ESRV agrees with concentrations of microseismic data. The ESRV accounts for $27.87 \%$ of the total SRV for the Eagle Ford well.

\section{ACKNOWLEDGMENTS}

This study was supported by the National Natural Science Foundation of China (51674279), National Basic Research Program of China (2014CB239103), Major National Research and Development Projects of China (2017ZX05049006), the Fundamental Research Funds for the Central Universities (17CX06010) and the Graduate Innovation Project of China University of Petroleum (East China) (YCXJ2016016).

\section{REFERENCES}

1. A. Islam and T. Patzek, Slip in natural gas flow through nanoporous shale reservoirs, J. Unconvent. Oil Gas Resour. 7 (2014) 49-54.

2. V. Shabro, C. Torres-Verdin and F. Javadpour, Numerical simulation of shale-gas production: From pore-scale modeling of slip-flow, Knudsen diffusion, and Langmuir desorption to reservoir modeling of compressible fluid, North American Unconventional Gas Conference and Exhibition (Society of Petroleum Engineers, 2011).

3. T. Lange, M. Sauter, M. Heitfeld et al., Hydraulic fracturing in unconventional gas reservoirs: Risks in the geological system part 1, Environ. Earth Sci. $\mathbf{7 0}$ (2013) 3839-3853.

4. Y. Jun, S. Hai, F. Dong-Yan et al., Transport mechanisms and numerical simulation of shale gas reservoirs, J. China Univ. Petrol. (Edn. Nat. Sci.) 37(1) (2013) 91-98.

5. B. Yuan, D. A. Wood and W. Yu, Stimulation and hydraulic fracturing technology in natural gas reservoirs: Theory and case studies (2012-2015), J. Nat. Gas Sci. Eng. 26 (2015) 1414-1421.

6. Q. Zhang, Y. Su, W. Wang et al., A new semianalytical model for simulating the effectively stimulated volume of fractured wells in tight reservoirs, J. Natu. Gas Sci. Eng. 27 (2015) 1834-1845.

7. B. Xu, X. Li, M. Haghighi et al., A new model for production analysis in naturally fractured shale gas reservoirs, J. China Univ. Petrol. Edn. Natu. Sci. 37(6) (2013) 92-99.

8. B. Yuan, Y. Su, R. G. Moghanloo et al., A new analytical multi-linear solution for gas flow toward fractured horizontal wells with different fracture intensity, J. Natu. Gas Sci. Eng. 23 (2015) 227-238.

9. D. M. Anderson, M. Nobakht, S. Moghadam et al., Analysis of production data from fractured shale gas wells, SPE Unconventional Gas Conference (Society of Petroleum Engineers, 2010).

10. D. Fan, A hybrid transient flow model for performance evaluation of shale gas reservoirs (Texas Tech School, 2015).

11. E. Stalgorova and L. Mattar, Practical analytical model to simulate production of horizontal wells with branch fractures. SPE Canadian Unconventional Resources Conference (Society of Petroleum Engineers, 2012).

12. S. C. Maxwell, T. I. Urbancic, N. Steinsberger et al., Microseismic imaging of hydraulic fracture complexity in the Barnett shale. SPE Annual Technical Conference and Exhibition (Society of Petroleum Engineers, 2002).

13. M. K. Fisher, C. A. Wright, B. M. Davidson et al., Integrating fracture mapping technologies to improve stimulations in the Barnett shale, $S P E$ Prod. Fac. 20(02) (2005) 85-93.

14. M. K. Fisher, J. R. Heinze, C. D. Harris et al., Optimizing horizontal completions in the Barnett shale with microseismic fracture mapping, J. Petrol. Technol. 57(3) (2005) 41-42.

15. Z. Boxiong, W. Zhongren, L. Rui et al., Review of microseismic monitoring technology research, Prog. Explorat. Geophys. 29(4) (2014) 1882-1888.

16. L. G. Griffin, C. A. Wright, S. L. Demetrius et al., Identification and implications of induced hydraulic fractures in waterfloods: Case history HGEU. SPE Permian Basin Oil and Gas Recovery Conference (Society of Petroleum Engineers, 2000).

17. L. G. Griffin, C. A. Wright, E. J. Davis et al., Surface and downhole tiltmeter mapping: An effective tool for monitoring downhole drill cuttings disposal, SPE 63032 (2000).

18. D. Astakhov, W. Roadarmel and A. Nanayakkara. A new method of characterizing the stimulated reservoir volume using tiltmeter-based surface microdeformation measurements. SPE Hydraulic Fracturing Technology Conference (Society of Petroleum Engineers, 2012).

19. M. Friedrich and M. Milliken, Determining the contributing reservoir volume from hydraulically fractured horizontal wells in the Wolfcamp formation in the Midland Basin, Unconventional Resources Technology Conference (URTEC) (2013).

20. A. Rahimi Zeynal, P. Snelling, C. W. Neuhaus et al., Correlation of stimulated rock volume from 
microseismic pointsets to production data-A horn river case study, SPE Western North American and Rocky Mountain Joint Meeting (Society of Petroleum Engineers, 2014).

21. D. Fan and A. Ettehadtavakkol, Semi-analytical modeling of shale gas flow through fractal induced fracture networks with microseismic data, Fuel 193 (2017) 444-459.

22. T. Miao, B. Yu, Y. Duan et al., A fractal analysis of permeability for fractured rocks, Int. J. Heat Mass Transf. 81 (2015) 75-80.

23. T. Miao, S. Yang, Z. Long et al., Fractal analysis of permeability of dual-porosity media embedded with random fractures, Int. J. Heat Mass Transf. 88 (2015) 814-821.

24. J. E. Olson, Multi-fracture propagation modeling: Applications to hydraulic fracturing in shales and tight gas sands, The 42nd US Rock Mechanics Symposium (USRMS) (American Rock Mechanics Association, 2008).

25. Z. Sun, J. Yao and D. Fan, Dynamic analysis of horizontal wells with complex fractures based on a discrete-fracture model, J. China Univ. Petrol. Edn. Natu. Sci. 38(2) (2014) 109-115.

26. X. Weng, Modeling of complex hydraulic fractures in naturally fractured formation, J. Unconvent. Oil Gas Resour. 9 (2015) 114-135.

27. X. Weng, O. Kresse, C. E. Cohen et al., Modeling of hydraulic-fracture-network propagation in a naturally fractured formation, SPE Product. Oper. 26(04) (2011) 368-380.

28. W. Xu, J. H. Le Calvez and M. J. Thiercelin, Characterization of hydraulically-induced fracture network using treatment and microseismic data in a tight-gas sand formation: A geomechanical approach, SPE Tight Gas Completions Conference (Society of Petroleum Engineers, 2009).

29. W. Xu, M. J. Thiercelin, U. Ganguly et al., Wiremesh: A novel shale fracturing simulator, International Oil and Gas Conference and Exhibition in China (Society of Petroleum Engineers, 2010).

30. B. R. Meyer and L. W. Bazan, A discrete fracture network model for hydraulically induced fractures-Theory, parametric and case studies, SPE Hydraulic Fracturing Technology Conference (Society of Petroleum Engineers, 2011).

31. P. Xu, B. Yu, Y. Feng et al., Permeability of the fractal disk-shaped branched network with tortuosity effect, Phys. Fluids (1994-Present) 18(7) (2006) 078103.

32. P. Xu, B. Yu, S. Qiu et al., An analysis of the radial flow in the heterogeneous porous media based on fractal and constructal tree networks, Phys. A: Stat. Mech. Appl. 387(26) (2008) 6471-6483.

33. F. Yang, Z. Ning and H. Liu, Fractal characteristics of shales from a shale gas reservoir in the Sichuan Basin, China, Fuel 115 (2014) 378-384.

34. M. Yun, B. Yu and J. Cai, A fractal model for the starting pressure gradient for Bingham fluids in porous media, Int. J. Heat Mass Transf. 51(5) (2008) 1402-1408.

35. P. Xu, C. Li, S. Qiu et al., A fractal network model for fractured porous media, Fractals 24 (2016) 1650018.

36. P. $\mathrm{Xu}, \mathrm{A}$ discussion on fractal models for transport physics of porous media, Fractals 23(03) (2015) 1530001.

37. Z. Zhou, Y. Su, W. Wang et al., Integration of microseismic and well production data for fracture network calibration with an L-system and rate transient analysis, J. Unconvent. Oil Gas Resour. 15 (2016) $113-121$.

38. Z. Zhou, Y. Su, W. Wang et al., Application of the fractal geometry theory on fracture network simulation, J. Petrol. Expl. Product. Technol. 7(2) (2017) 487-496.

39. K. L. Hoffman and T. K. Ralphs, Integer and combinatorial optimization, in Encyclopedia of Operations Research and Management Science (Springer, US, 2013), pp. 771-783.

40. B. Yu and J. Li, Some fractal characters of porous media, Fractals 9(03) (2001) 365-372.

41. G. Sheng, Y. Su, W. Wang, J. Liu, M. Lu, Q. Zhang and L. Ren, A multiple porosity media model for multi-fractured horizontal wells in shale gas reservoirs, J. Nat. Gas Sci. Eng. 27 (2015) 162-1573.

42. I. Y. Akkutlu and E. Fathi, Multiscale gas transport in shales with local Kerogen heterogeneities, SPE J. 17(04) (2012) 1002-1011.

43. F. Civan, Effective correlation of apparent gas permeability in tight porous media, Transp. Porous Media 82(2) (2010) 375-384.

44. X. Chen, J. Li, M. Zheng, et al., Kerogen solution theory and its exploratory application in shale gas assessment, Nat. Gas Geosci. 23(1) (2012) 14-18.

45. F. Javadpour, D. Fisher and M. Unsworth, Nanoscale gas flow in shale gas sediments, J. Can. Petrol. Technol. 46(10) (2007) 55-61.

46. F. Javadpour, Nanopores and apparent permeability of gas flow in mudrocks (shales and siltstone), J. Can. Petrol. Technol. 48(8) (2009) 16-21.

47. B. Yan, Y. Wang and J. E. Killough, Beyond dualporosity modeling for the simulation of complex flow mechanisms in shale reservoirs, Comput. Geosci. 20(1) (2016) 69-91. 